\title{
Determination of Appropriate Axial Vibration Dampers for a Naval Vessel Driven by CODAG Propulsion
}

\author{
Abdullah Gokturk ${ }^{1,2}$, Osman Azmi Ozsoysal ${ }^{1}$ \\ ${ }^{1}$ Departement of Naval Architecture and Marine Engineering, Istanbul Technical University \\ ${ }^{2}$ Departement of Naval Architecture and Marine Engineering, Iskenderun Technical University
}

\begin{tabular}{l} 
Article Info \\
\hline Article history: \\
Received May $30^{\text {th }}, 2017$ \\
Revised Aug $20^{\text {th }}, 2017$ \\
Accepted Oct $18^{\text {th }}, 2017$ \\
\hline
\end{tabular}

\section{Keyword:}

Axial dampers

Vibration

Naval vessel

Codag propulsion

Simulink

\begin{abstract}
The objective of this study is to reduce the vibration oscillations on a naval vessel propulsion system driven by CODAG. Within vibration analysis of the system firstly; physical model of the naval ship's propulsion system consist of mass, spring and damping elements developed properly and the effects of dynamic forces, which are consisted of main engine stresses, and the hydrodynamic forces that come from water effect are also taken into consideration. Afterwards, equation of motions derived for each mass and consequently by solving these equations, employing matrix approach, natural frequencies and modes of the axial vibration obtained. Finally, a model for propulsion system formed in Matlab/Simulink program. The axial vibrations caused by internal and external forces that excite the system examined and illustrated with graphs how the model respond in the face of undamped and under different axial damping ratios. Then which is also our goal; axial damping ratios that can absorb vibrational motions of the system successfully determined.
\end{abstract}

\section{Corresponding Author:}

First Author,

Departement of Naval Architecture and Marine Engineering,

Istanbul Technical University,

Ayazaga Campus, MaslakSariyer, Istanbul31200, Turkey.

Email: goktura@itu.edu.tr

\section{Introduction}

Recent advances in ship design has led to build greater in size and more flexible vessels employ more powerful diesel engines with larger strokes. Flexibility in these structures brings about vibration problems. The main sources of ship vibration can be classified into two major groups; internal and external sources. Internal sources are main \& auxilary machines and propulsion system components and the external sources are hydrodinamic loadings by direct action or induced by the ship motions.

Vibration aboard ship may result in fatigue failure of local structural members or major machinery components, adversly effect the performance of vital shipboard equipment, increase maintenance costs and greatly increase discomfort or annoyyance to passengers and crew. These all are why excessive ship vibrations must be taken under control. However, when ship is sailing, corrections on the vessel to decrease vibration problems is too difficult and couses great costs. Therefore, it is very important to identify and make corrections of vibration problems in design stage[1].

Antonides [2], made measurements on the propulsion system of the USS Simon Lake (AS-33) as a part of a program to improve analysis procedures used by the navy for predicting the longitudinal vibration of shaft 
propulsion system. The objective was to find the axial exciting forces and damping associated with the propulsion system of the ship, as well as to determine how the gear case, turbines, condenser, and machineryfoundation effect longitudinal vibration. Alternating thrust in the shaft and longitudinal displacement of the gear case, low-pressure turbine condenser and machinery foundation was measured. A resonance was found to exist in the operating range, but is not considered detrimental. The gear case, turbines and condenser move essentially as one unit. A mass-elastic system derived from measured data includes a level effect acting on the foundation mass. The exciting forces were lower than usual, except at or near full power.

Alarcin at al. [3], on their study were concern with to decrease of vibration oscillations on ship main engine shaft system. The mathematics model of system was composed by Lagrange method and the effect of dynamics forces, which are consisted of main engine stresses, and the hydrodynamic forces that come from water effect were taken into consideration. The axial and torsional vibration are the factors during the analyze. Matlab-Simulink was used to obtain the oscillation of axial and torsional vibrations and to make these oscillations less different types of damping coefficient effects were investigated.

Zhang at al.[4] by modelling of the propeller shaft crankshaft with piston under the influence of angular and axial forces acting on the propeller was investigated. Between propeller and $1^{\text {st }}$ order crankshaft journal, $5^{\text {th }}$ and $6^{\text {th }}$ order piston-crank journal's shaft torsional vibrations have been observed frequency change. Axial vibrations, except for the amplitude, a change of frequency components are expressed almost the same. Considering of coupled vibrations a nonlinear behavior effect was observed. They determined that when the propeller crankshaft vibration analysis approaches to linearity, a large error would be experienced.

Jiang at al. [5] studied the vibration performance of the propulsion shaft introduced by the coupling effect of the propeller and diesel engine. Firstly, the empirical formulas of the exciting force introduced by the diesel and propeller were given. Then a finite element model of propulsion shaft was established with ANSYS. Meanwhile the dynamic responses of the shaft introduced by the diesel excitation, the propeller excitation and the coupling effect of the two excitation were obtained respectively. The research results show that well matched diesel-propeller contributes to the vibration reduction of the propulsion shaft.

Several operations can be done at the ship design stage to reduce the excessive ship vibrations:

- reducing exciting forces amplitude,

- increasing stiffness,

- avoid values of frequency ratio near resonant condition and

- increasing damping ratios.

Avoiding vibrations by increasing damping ratios is the main objective of this study

\section{CODAG Propulsion System Vibration Modelling}

The main sources of axial vibrations in ship propulsion systems are the diesel engine crank mechanism, which produces the power needed for propeller propulsion and propulsion systems. Therefore, when axial vibration analysis is carried out, propeller characteristics, thrust generated and diesel engine characteristics must be well determined.

CODAG (Combined Diesel and Gas) is a type of propulsion system for ships which need a maximum speed that is considerably faster than their cruise speed, particularly warships like modern frigates or corvettes. It consists of diesel engines for cruising and gas turbines that can be switched on for high-speed transits. In figure 1, a simplified 3D model for CODAG propulsion system is represented and relevant to this model, idealized mass, spring and damping system for axial vibration analysis is shown in figure 2. 


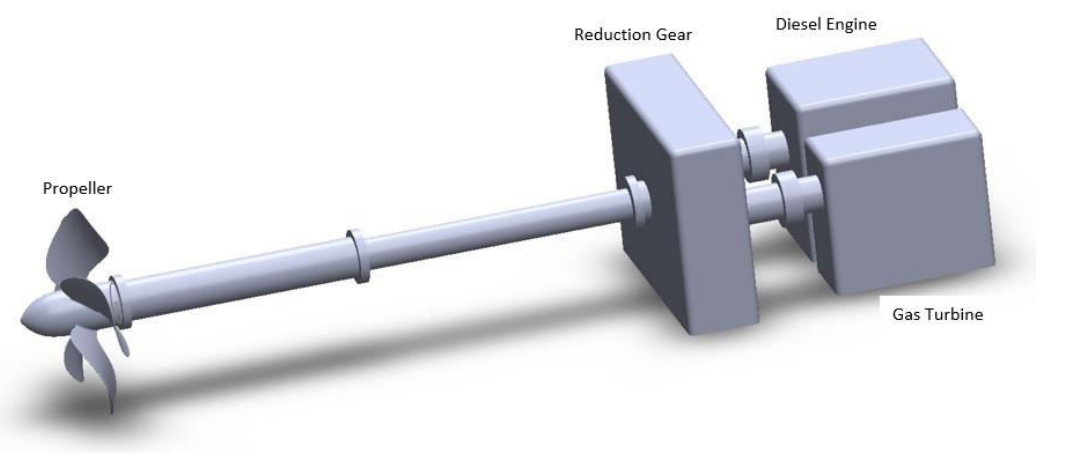

Figure 1. CODAG propulsion system simplified 3D model.

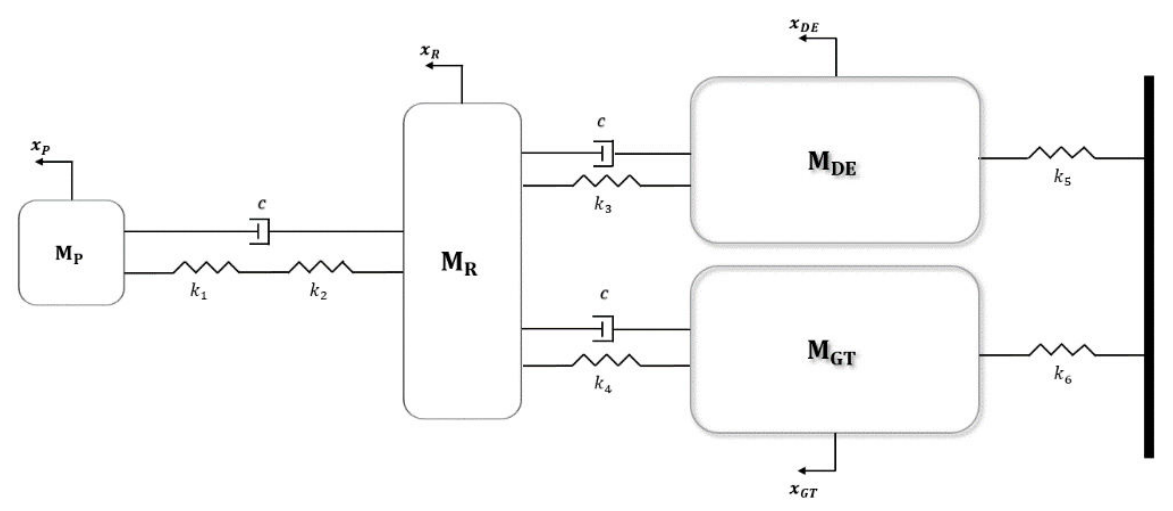

Figure 2. Idealized mass, spring, damping system.

Equations of motion for the system derived from mass spring damping system, as shown below:

$M_{P} \ddot{x}_{P}+c\left(\dot{x}_{P}-\dot{x}_{R}\right)+k_{e}\left(x_{P}-x_{R}\right)=T$

$M_{R} \ddot{x}_{R}-c\left(\dot{x}_{P}-\dot{x}_{R}\right)+c\left(\dot{x}_{R}-\dot{x}_{D E}\right)+c\left(\dot{x}_{R}-\dot{x}_{G T}\right)-k_{e}\left(x_{P}-x_{R}\right)+$

$+k_{3}\left(x_{R}-x_{D E}\right)+k_{4}\left(x_{R}-x_{G T}\right)=F_{R}$

$M_{D E} \ddot{x}_{D E}-c\left(\dot{x}_{R}-\dot{x}_{D E}\right)-k_{3}\left(x_{R}-x_{D E}\right)+k_{5} x_{D E}=0$

$M_{G T} \ddot{x}_{G T}-c\left(\dot{x}_{R}-\dot{x}_{G T}\right)-k_{4}\left(x_{R}-x_{G T}\right)+k_{6} x_{G T}=0$

In order to write differential equations expressing the dynamic behavior of the system in matrix form, it is necessary to specify the mass, damping and stiffness matrices of these equations. The matrix expression for the equations of motion is:

$$
\begin{aligned}
& {\left[\begin{array}{cccc}
M_{P} & 0 & 0 & 0 \\
0 & M_{R} & 0 & 0 \\
0 & 0 & M_{D E} & 0 \\
0 & 0 & 0 & M_{G T}
\end{array}\right]+\left\{\begin{array}{c}
\ddot{x}_{P} \\
\ddot{x}_{R} \\
\ddot{x}_{D E} \\
\ddot{x}_{G T}
\end{array}\right\}+\left[\begin{array}{cccc}
c & -c & 0 & 0 \\
-c & 3 c & -c & -c \\
0 & -c & c & 0 \\
0 & -c & 0 & c
\end{array}\right]\left\{\begin{array}{c}
\dot{x}_{P} \\
\dot{x}_{R} \\
\dot{x}_{D E} \\
\dot{x}_{G T}
\end{array}\right\}} \\
& {\left[\begin{array}{cccc}
k_{e} & -k_{e} & 0 & 0 \\
-k_{e} & k_{e}+k_{3}+k_{4} & -k_{3} & -k_{4} \\
0 & -k_{3} & k_{3}+k_{5} & 0 \\
0 & -k_{4} & 0 & k_{4}+k_{6}
\end{array}\right]\left\{\begin{array}{c}
x_{P} \\
x_{R} \\
x_{D E} \\
x_{G T}
\end{array}\right\}=\left\{\begin{array}{c}
T \\
F_{R} \\
0 \\
0
\end{array}\right\}}
\end{aligned}
$$

$\mathrm{T}$ isthe thrust, which obtained at maximum power in the case of attaching to a fixed point. $\mathrm{F}_{\mathrm{R}}$ is the force generated by the reduction gear. The natural frequency is a value that depends on its own mass and rigidity. Therefore, these values are not taken into account since there is no effect of force and damping on calculation of natural frequency. 


$$
\left[\begin{array}{cccc}
M_{P} & 0 & 0 & 0 \\
0 & M_{R} & 0 & 0 \\
0 & 0 & M_{D E} & 0 \\
0 & 0 & 0 & M_{G T}
\end{array}\right]+\left\{\begin{array}{c}
\ddot{x}_{P} \\
\ddot{x}_{R} \\
\ddot{x}_{D E} \\
\ddot{x}_{G T}
\end{array}\right\}+\left[\begin{array}{cccc}
k_{e} & -k_{e} & 0 & 0 \\
-k_{e} & k_{e}+k_{3}+k_{4} & -k_{3} & -k_{4} \\
0 & -k_{3} & k_{3}+k_{5} & 0 \\
0 & -k_{4} & 0 & k_{4}+k_{6}
\end{array}\right]\left\{\begin{array}{c}
x_{P} \\
x_{R} \\
x_{D E} \\
x_{G T}
\end{array}\right\}=\left\{\begin{array}{l}
0 \\
0 \\
0 \\
0
\end{array}\right\}
$$

In order to calculate natural frequency we should solve the eigenvalue problem for the system.

$$
\begin{gathered}
\left|[K]-w^{2}[M]\right|=0 \\
\|\left[\begin{array}{cccc}
k_{e} & -k_{e} & 0 & 0 \\
-k_{e} & k_{e}+k_{3}+k_{4} & -k_{3} & -k_{4} \\
0 & -k_{3} & k_{3}+k_{5} & 0 \\
0 & -k_{4} & 0 & k_{4}+k_{6}
\end{array}\right]-w^{2}\left[\begin{array}{cccc}
M_{P} & 0 & 0 & 0 \\
0 & M_{R} & 0 & 0 \\
0 & 0 & M_{D E} & 0 \\
0 & 0 & 0 & M_{G T}
\end{array}\right]=\left\{\begin{array}{l}
0 \\
0 \\
0 \\
0
\end{array}\right\}
\end{gathered}
$$

We need the values of parameters to solve eq. (2) and find natural frequencies for the system. Table 1 represents shaft characteristics for the propulsion system and there is mass and force values shown in Table 2. Additionally, shaft rigidity values (k) are calculated based on shaft properties and shown in Table 2.

Table 1. Shaft dimensions.

\begin{tabular}{ccc}
\hline Shaft Type & Shaft Diameter $(\mathrm{mm})$ & Shaft Length $(\mathrm{mm})$ \\
\hline Propeller shaft & 480 & 14250 \\
Intermediate shaft & 420 & 14900 \\
Diesel engine thrust shaft & 400 & 3600 \\
Gas turbine thrust shaft & 400 & 3600 \\
\hline
\end{tabular}

Table 2. Mass, spring system parameters.

\begin{tabular}{ccccccc}
\hline $\mathrm{M}_{\mathrm{P}}$ & $\mathrm{M}_{\mathrm{R}}$ & $\mathrm{M}_{\mathrm{DE}}$ & $\mathrm{M}_{\mathrm{GT}}$ & $\mathrm{T}$ & $\mathrm{F}_{\mathrm{R}}$ & $\mathrm{k}_{\mathrm{e}}$ \\
\hline 13400 & 32300 & 13400 & 15000 & 197137 & $2.67 \times 10^{9}$ & $1.13 \times 10^{9}$ \\
$\mathrm{~kg}$ & $\mathrm{~kg}$ & $\mathrm{~kg}$ & $\mathrm{~kg}$ & $\mathrm{~N}$ & $\mathrm{~N} / \mathrm{m}$ & $\mathrm{N} / \mathrm{m}$ \\
\hline $\mathrm{k}_{1}$ & $\mathrm{k}_{2}$ & $\mathrm{k}_{3}$ & $\mathrm{k}_{4}$ & $\mathrm{k}_{5}$ & $\mathrm{k}_{6}$ \\
\hline $2.67 \times 10^{9}$ & $1.95 \times 10^{9}$ & $7.33 \times 10^{9}$ & $7.33 \times 10^{9}$ & $1.29 \times 10^{9}$ & $1.87 \times 10^{9}$ \\
$\mathrm{Ns} / \mathrm{m}$ & $\mathrm{Ns} / \mathrm{m}$ & $\mathrm{Ns} / \mathrm{m}$ & $\mathrm{Ns} / \mathrm{m}$ & $\mathrm{Ns} / \mathrm{m}$ & $\mathrm{Ns} / \mathrm{m}$ \\
\hline
\end{tabular}

By solving the eq. (2), frequencies of the system is found and shown in Table 3.

Table 3. Natural frequency of the system.

\begin{tabular}{cc}
\hline & Frequency $(\mathrm{Hz})$ \\
\hline $\mathrm{w}_{1}$ & 2.306 \\
$\mathrm{w}_{2}$ & 14.592 \\
$\mathrm{w}_{3}$ & 468.792 \\
$\mathrm{w}_{4}$ & 1256.433 \\
\hline
\end{tabular}




\section{Simulation}

The vibrations of the CODAG propulsion system components in axial directions are analyzed by simulating various damping values with $\mathrm{m}$-file and Simulink model files created in Matlab/Simulink program as shown in Figure 3.

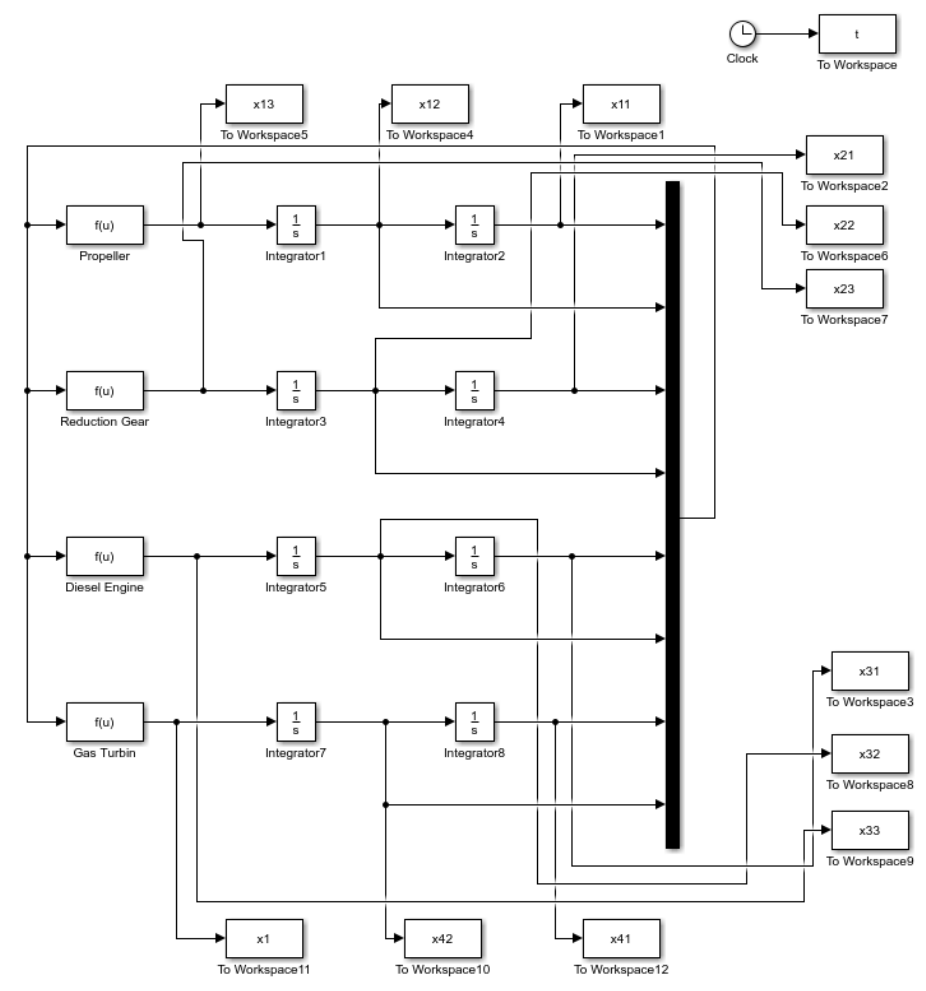

Figure 3. CODAG propulsion system Simulink model.

As a result of the analysis of the axial vibrations of the CODAG propulsion system elements at undamped and different damping ratios, the amplitude variations of axial displacements and the velocities of the propeller, reduction gear, diesel engine and gas turbine are illustrated in graphs respectively.

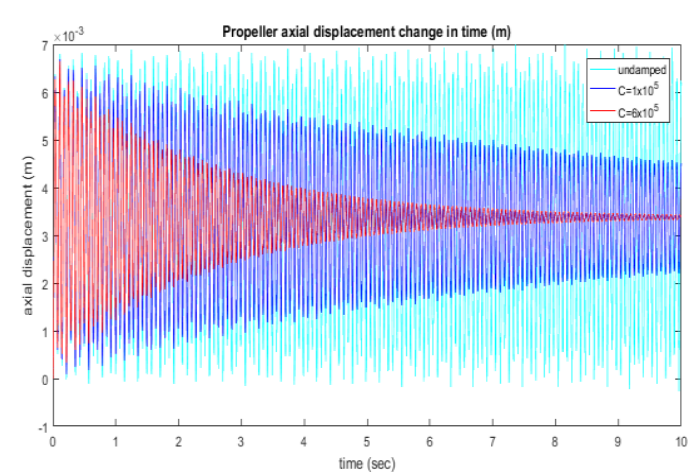

Figure 4. (a) Propeller axial displacement change in

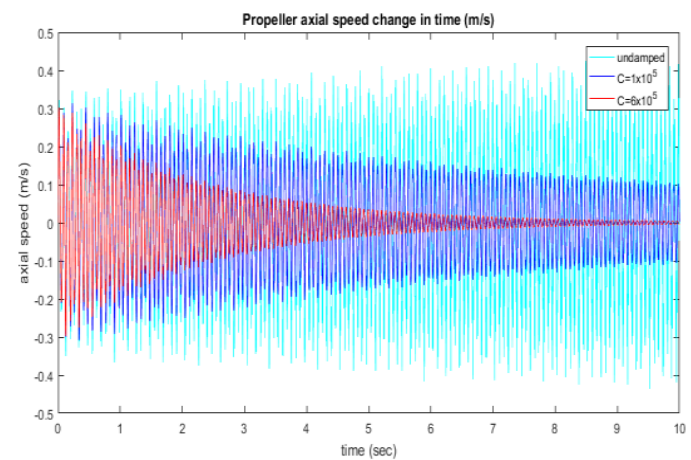

(b) Propeller axial speed change in time $(\mathrm{m} / \mathrm{sec})$.

time $(m)$ 


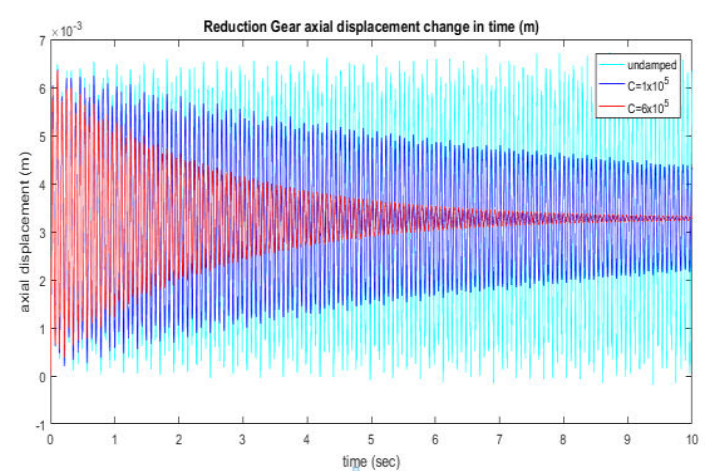

Figure 5. (a) Reduction Gear axial displacement change in time (m).

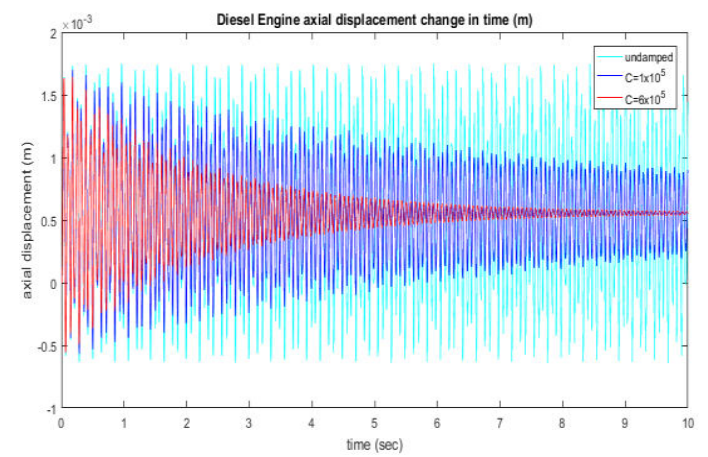

Figure 6. (a) Diesel Engine axial displacement change in time(m).

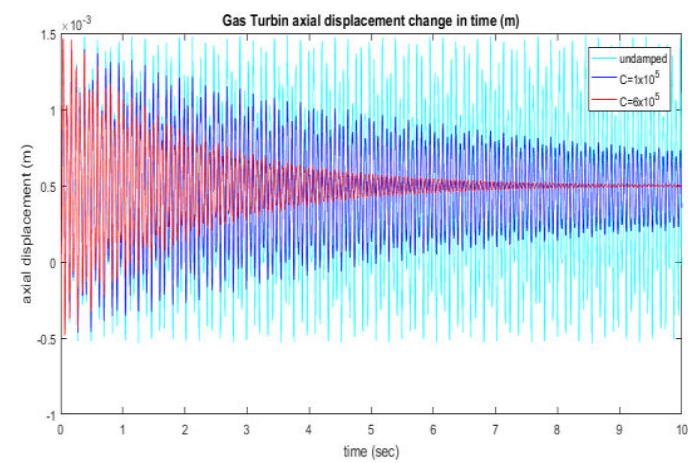

Figure 7. (a) Gas Turbin axial displacement change in

time (m).

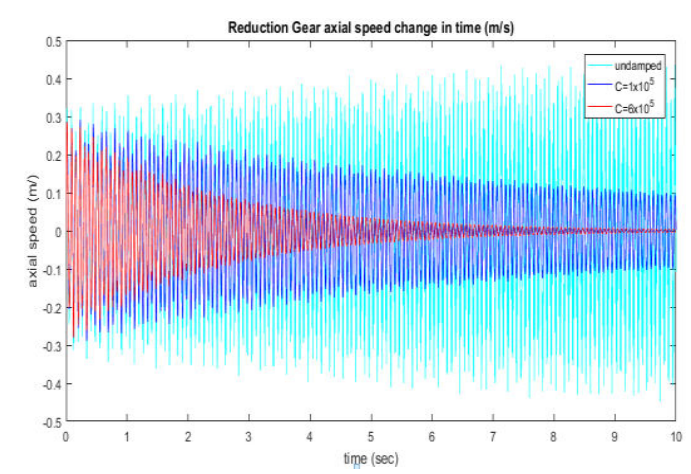

(b) Reduction Gear axial speed change in time

$(\mathrm{m} / \mathrm{sec})$

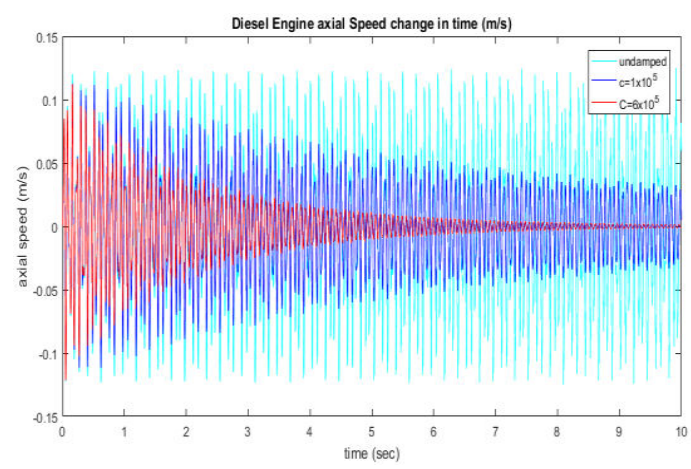

(b) Diesel Engine axial speed change in time

$(\mathrm{m} / \mathrm{sec})$.

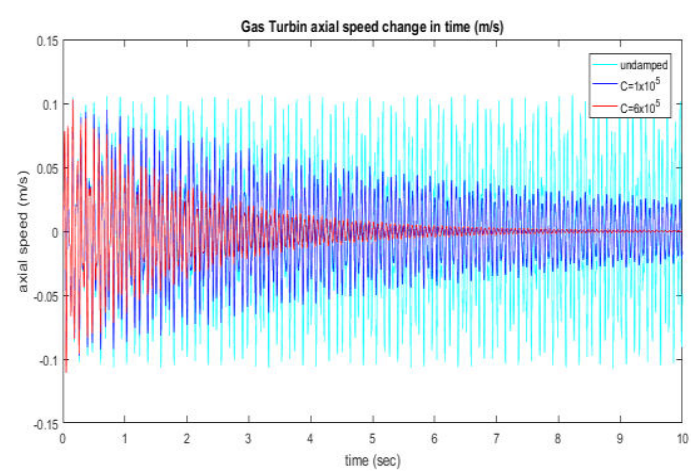

(b) Gas Turbin axial speed change in time

$(\mathrm{m} / \mathrm{sec})$.

Considering the simulation, by applying the axial damping coefficients from $1 \times 10^{5} \mathrm{Ns} / \mathrm{m}$ to $6 \times 10^{5} \mathrm{Ns} / \mathrm{m}$, the damping ratios changes from $27.34 \%$ to $45.46 \%$ for propeller axial displacement,and changes from $76.2 \%$ to $88.3 \%$.for propeller axial velocity. Damping ratios for reduction gear axial displacement, changes from $30.7 \%$ to $47.2 \%$ and for reduction gear axial velocity, changes from $77.3 \%$ to $89.7 \%$.Damping ratios for diesel engine axial displacement, changes from $36.7 \%$ to $55.3 \%$ and for diesel engine axial velocity, changes from $79.4 \%$ to $93.6 \%$.Damping ratios for diesel engine axial displacement, changes from $39.8 \%$ to $56.7 \%$ and for diesel engine axial velocity, changes from $81.2 \%$ to $94.9 \%$.

\section{Conclusion}

In this study, the propulsion system vibrations of a naval vessel driven by CODAG are investigated. Firstly, the propulsion system is modeled separately as mass-spring-damping element, equations of motion for each 
mass are obtained and dynamic behavior of the system in nature is observed by neglecting the effect of force and damping elements. The system is also modeled using Matlab/Simulink program for the case when the system is in operation, that is, the system is under the influence of excitations and damping elements. Axial vibrations due to internal and external forces acting on the system are analyzed and how the model responds to undampedand different damping conditions is illustrated. The axial damping coefficient, $\mathrm{C}=6 \times 10^{5} \mathrm{Ns} / \mathrm{m}$, that can successfully absorb the oscillatory motion of the system in the axial direction has been determined.

\section{References}

[1]. American Bureau of Shipping, "Guidance Notes on Ship Vibration.” 2006.

[2]. G. Antonides, "Longitudinal vibration of propulsion system on USS Simon Lake (AS-33)." Acoustics and Vibration Laboratory Research and Development Report, Report 2147, S-F0131108 Task 01351, 1966.

[3]. F. Alarcin and F.C. Korkmaz "Vibration analysis of ship main engine and shaft system," Journal of Engineering and Natural Sciences, Sigma 3, 2012, pp.310-319.

[4]. G. Zhang, Y. Zhao, T. Li, and X. Zhu, "Propeller excitation of longitudinal vibration characteristics of marine propulsion shafting system," Hindawi Publishing Corporation Shock and Vibration, 2014, Article ID 413592, 19 pages.

[5]. X. Jiang, X. Zhou and K. Chen, "Vibration characteristics of a marine propulsion shaft excited by the effect of propeller and diesel," Transportation Information and Safety (ICTIS, International Conference on, Whuan, 2015, pp. 893-897.

[6]. MTU, “Technical Sales Documentations,” Friedrichshafen, Germany, 2011. 